\title{
Angioedema suppressed by a combination of anti-histamine and leukotriene modifier
}

\author{
Brendan N. Wong and Peter Vadas*
}

\begin{abstract}
Rationale: Angioedema without co-existent urticaria is due to a limited number of causes, including hereditary and acquired C1 esterase inhibitor deficiency, drug-induced angioedema or idiopathic histaminergic or non-histaminergic angioedema. We describe a cohort of patients with recurrent angioedema whose clinical features and response to medications are distinct from the causes above.

Methods: Patients were accrued retrospectively from an academic allergy practice between 2007 and 2014. After institutional research ethics board approval, patients' charts were reviewed and demographic, clinical and laboratory data were extracted.

Results: A total of 11 patients were recruited. The mean age at presentation was 54.9 years (range 19-70 years) and 6 of 11 were male. The mean number of episodes per year was 18.7 (range 2-60) and mean duration of episodes was $22.4 \mathrm{~h}$ (range 4-96). About half of episodes (52\%) began overnight. Areas of involvement were lips (73\%), tongue (64\%), eyelids (18\%), feet (36\%) and hands (27\%). None of the patients had low C3, C4, or CH50; none had significantly positive ANA; $\mathrm{C} 1$ esterase inhibitor level and function and C1q were normal in all patients tested. In these 11 patients, complete suppression of recurrences by the combination of cetirizine $20 \mathrm{mg}$ daily and montelukast $10 \mathrm{mg}$ daily was reported by 9 (82\%) of patients; whereas $2(18 \%)$ of patients had a partial response to this combination of medications.
\end{abstract}

Conclusions: Herein, we report a form of angioedema without urticaria, mediated by a combination of histamine and leukotrienes. Clinical, demographic and therapeutic characteristics differentiate this from other recognized causes of angioedema.

Keywords: Angioedema, Urticaria, Histaminergic, Non-histaminergic, Anti-histamines, Leukotriene receptor antagonist, Cetirizine, Montelukast

\section{Background}

Angioedema is the non-pitting swelling of the subcutaneous or submucosal tissues, caused by a transient increase in capillary permeability. Episodes of swelling usually last from a few hours to several days, and frequency of recurrences may vary from a few times per week to a few times per year.

Angioedema has been classified into two broad categories: with or without co-existent urticaria. Acute episodic

\footnotetext{
*Correspondence: vadasp@smh.ca Division of Allergy and Clinical Immunology, Department of Medicine, St. Michael's Hospital, Toronto, Canada
}

angioedema with urticaria is relatively commonplace. Recognized causes include chronic spontaneous and inducible urticaria and reactions to foods, venoms, latex, drugs, or physical triggers [1]. In contrast, angioedema without urticaria is considerably less common, occurring $2.4 \%$ of the time [2]. Angioedema without urticaria may be due to congenital $\mathrm{C} 1$ esterase inhibitor deficiency [type I hereditary angioedema (HAE)], dysfunctional $\mathrm{C} 1$ esterase inhibitor (type II HAE) and hereditary angioedema with normal $\mathrm{C} 1$ inhibitor and mutations in the factor XII gene [1, 3, 4]. Kinin-mediated angioedema associated with angiotensin converting enzyme inhibitors 
and direct renin inhibitors presents without urticaria [1]. HAE, acquired $\mathrm{C} 1$ esterase inhibitor deficiency and druginduced angioedema, have been well characterized and the mechanisms and mediators are elucidated.

After having ruled out the causes above, more than one-third of cases of angioedema are classified as idiopathic. Histaminergic and non-histaminergic angioedema are two distinct forms of idiopathic angioedema that have been characterized thus far in the literature. In a large cohort of 776 patients with angioedema but without urticaria, $16 \%$ were caused by drugs, insect stings or foods; $11 \%$ due to angiotensin converting enzyme inhibitors; $7 \%$ due to autoimmune disease or infection and $25 \%$ due to $\mathrm{C} 1$ esterase inhibitor deficiency [5]. In the remaining $41 \%$ of cases, $33 \%$ had idiopathic histaminergic and $5 \%$ had idiopathic non-histaminergic angioedema. Whereas histaminergic angioedema is suppressed by first and second generation $\mathrm{H} 1$ anti-histamines, idiopathic non-histaminergic angioedema may be responsive to other agents, such as steroids, dapsone, rituximab and icatibant [6-8].

Herein, we describe a form of recurrent angioedema which appears to be distinct from histaminergic and non-histaminergic forms in that it is responsive to a combination of anti-histamine and leukotriene receptor antagonist (LRA).

\section{Methods}

A cohort of 11 patients was accrued retrospectively from an academic allergy practice from 2007 to 2014. Following institutional research ethics board approval, patients' charts were reviewed and demographic, clinical, and laboratory data were extracted. Patients were included in this study when other recognized causes of angioedema were ruled out by history, laboratory investigations, and whose angioedema was either completely or partially suppressed by a combination of antihistamine and leukotriene receptor antagonist.

The location, timing, frequency and clinical characteristics of angioedema were elicited. Family history of angioedema, medication use, relevant exposures prior to recurrences, potential triggers such as infection, stress, trauma and others were recorded. Laboratory investigations included $\mathrm{C} 3, \mathrm{C} 4, \mathrm{CH} 50$ and $\mathrm{C1q}$ complement studies, anti-nuclear antibody (ANA), C1 esterase inhibitor antigen level, and $\mathrm{C} 1$ esterase inhibitor functional assay determinations.

\section{Results}

A total of 11 patients with angioedema were identified whose characteristics fulfilled the criteria above. There were 6 males (55\%) and 5 females (45\%). Mean age of onset of angioedema occurred at 51.7 years (range
13-64 years). Mean age at first assessment was 54.9 years (range 19-70 years).

Mean number of episodes per year was 18.7 (range 2-60 episodes), and $52.0 \%$ (range $0-100 \%$ ) of those episodes began overnight. Mean duration of those episodes was 22.4 h (range 4-96 h).

Anatomic localization of angioedema was as follows: $73 \%$ of patients had swelling of the lips, $64 \%$ of the tongue, $45 \%$ of the cheeks, $36 \%$ of the feet, $27 \%$ of the hands, $18 \%$ of the eyelids, $18 \%$ of genitalia, $18 \%$ of the neck, $18 \%$ of the throat and $18 \%$ of the face.

In 4 of 11 patients, the angioedema was bland (36\%), whereas 7 of 11 (64\%) experienced pareasthesia.

Whereas 2 patients were taking angiotensin-converting-enzyme (ACE) inhibitors (18\%), 1 patient was taking an angiotensin II receptor blocker (9\%) and 1 patient was on a direct renin inhibitor (9\%), discontinuation of these medications did not lead to resolution of recurrent angioedema after a minimum of 6 months. None of the 11 patients in this study had a family history of angioedema.

Laboratory investigations were performed in all patients to rule out connective tissue diseases and $\mathrm{C} 1$ esterase inhibitor deficiency. 11 patients (100\%) had negative antinuclear antibody (ANA) screening assays. All patients (100\%) had normal levels of C3, C4, CH50, $\mathrm{C} 1 \mathrm{q}, \mathrm{C} 1$ esterase inhibitor levels and $\mathrm{C} 1$ esterase inhibitor functional assays.

All 11 patients consented to suppressive therapy, These 11 patients were initially treated with high dose cetirizine ( $40 \mathrm{mg}$ daily). None of the 11 patients treated with cetirizine alone reported complete suppression of angioedema. These 11 patients were then treated with a combination of cetirizine $20 \mathrm{mg}$ once daily and montelukast $10 \mathrm{mg}$ once daily. Of these 11 patients, 9 patients (82\%) had complete suppression using a combination of cetirizine $20 \mathrm{mg}$ daily and montelukast $10 \mathrm{mg}$ daily; and the remaining 2 of 11 patients (18\%) given cetirizine and montelukast had partial suppression (50 and 66\% respectively) of recurrences.

\section{Discussion}

Idiopathic angioedema is generally classified into either histaminergic or non-histaminergic forms. The idiopathic histaminergic form responds to treatment with antihistamine monotherapy. Idiopathic non-histaminergic angioedema may respond to a variety of medications, including steroids, dapsone, rituximab, icatibant (a bradykinin receptor antagonist), ecallantide (a kallikrein inhibitor), C1 esterase inhibitor concentrate, tranexamic acid, cannabis and omalizumab [6-13]. Neither group has distinguishable laboratory features [2]; however, the two groups differ in demographics and clinical features. 
Idiopathic histaminergic angioedema has no sex predilection and tends to occur equally in males and females. Attacks of idiopathic histaminergic angioedema respond to antihistamines for both acute treatment and long-term suppression [5]. The mean age of presentation is 50 years, with mean duration of attacks of $28.1 \mathrm{~h}$ [14]. Upper airway involvement was reported in $54.8 \%$ and tongue swelling in $29 \%$ of patients. All patients responded to antihistamine therapy.

Idiopathic non-histaminergic angioedema tends to occur more often in males, with the age of onset beginning at a considerably younger age. Episodes may also affect cutaneous sites and abdominal organs, but are not known to affect the lips and tongue. Mansi et al. described a large cohort of 1058 patients with angioedema without urticaria [15]. Of these, 377 had hereditary and 681 acquired angioedema. 49 of 681 had acquired $\mathrm{C} 1$ esterase inhibitor deficiency and 183 had angioedema secondary to angiotensin converting enzyme inhibitors. Idiopathic histaminergic angioedema was diagnosed in 379 patients and idiopathic non-histaminergic angioedema was diagnosed in 70 patients. The median age of onset of non-histaminergic angioedema was 38 years, with a median duration of attacks of $48 \mathrm{~h}$. More than $80 \%$ of patients with non-histaminergic angioedema reported more than 5 attacks per year. Attacks were reported in the face in $86 \%$; tongue and oropharynx (55\%); extremities (56\%) and gastrointestinal tract in $20 \%$. A response to tranexamic acid was seen in 37 of 38 patients who consented to treatment [15].

In the cohort described in our series, the angioedema seems to be mediated by a combination of histamine and leukotrienes, in that partial or complete suppression of recurrences is seen by using a combination of receptor antagonists to these two mediators. The prevalence of this form was equal in males and females, with a mean age of onset of 52 years. The mean duration of attacks was $22.4 \mathrm{~h}$. Most patients had involvement of the head and neck, $18 \%$ had involvement of the upper airway. None of our patients had abdominal attacks. Angioedema was not suppressed by high dose antihistamine monotherapy, whereas the combination of antihistamine and montelukast was effective. This form of angioedema often begins unprovoked overnight, possibly due to the nocturnal drop in endogenous cortisol.

The clinical course of angioedema is not benign, in that significant numbers of patients may experience upper airway involvement, although none of the patients required intubation for airway compromise. Nevertheless, patients diagnosed with this form of angioedema should be provided with an epinephrine auto-injector.

Angioedema responsive to a combination of anti-histamine and leukotriene modifier drugs does not imply a previously unreported form of angioedema, but does suggest that a combination of histamine and leukotrienes may contribute to recurrences of angioedema in some patients. Whether angioedema in these patients is unique and distinct from previously reported forms remains to be determined and will require further investigation. Specifically, non-histaminergic forms of angioedema responsive to other drugs, such as steroids, rituximab, tranexamic acid and dapsone will have to be investigated for their response to the combination of histamine and leukotriene antagonists.

\section{Conclusions}

Angioedema without urticaria may be due to many causes, and a systematic approach to investigation and treatment is required. Where clinical evaluation and laboratory investigations have ruled out medications, autoimmunity, infection and $\mathrm{C} 1$ esterase inhibitor deficiency, idiopathic forms of angioedema may be considered. This latter category appears to have 3 subtypes: namely, idiopathic histaminergic angioedema, idiopathic non-histaminergic angioedema and idiopathic histamine- and leukotriene-mediated angioedema. This latter form of angioedema appears to be distinct from the other idiopathic types based on the clinical profile of affected patients and their response to suppressive therapy.

\section{Authors' contributions}

BNW was a summer student under the supervision of PV. BNW extracted and compiled data from charts, performed statistical analysis and prepared a preliminary draft of the manuscript. PV generated the hypothesis, identified patients for inclusion, supervised BNW and prepared the manuscript for submission. Both authors read and approved the final manuscript.

Competing interests

The authors declare that they have no competing interests.

Availability of data and materials

The datasets used and/or analysed during the current study available from the corresponding author on reasonable request.

Ethics approval and consent to participate

This study was approved by the Research Ethics Board of St. Michael's Hospital.

\section{Funding}

This study was self-funded.

\section{Publisher's Note}

Springer Nature remains neutral with regard to jurisdictional claims in published maps and institutional affiliations.

Received: 18 December 2016 Accepted: 26 May 2017

Published online: 13 June 2017

References

1. Cicardi M, Aberer W, Banerji A, Bas M, Bernstein JA, Bork K, Caballero T, Farkas H, Grumach A, Kaplan AP, Riedl MA, Triggiani M, Zanichelli A, Zuraw B. HAWK under the patronage of EAACI (European Academy of Allergy and Clinical Immunology). Classification, diagnosis, and approach to 
treatment for angioedema: consensus report from the Hereditary Angioedema International Working Group. Allergy. 2014;69(5):602-16.

2. Eli M, Joseph M, Kuznik B, Menachem S. Chronic idiopathic angioedema: a single center experience. Int J Dermatol. 2014;53(10):e421-7.

3. Wu MA, Perego F, Zanichelli A, Cicardi M. Angioedema phenotypes: disease expression and classification. Clin Rev Allergy Immunol. 2016:51(2):162-9.

4. Farkas H, Veszeli N, Kajdácsi E, Cervenak L, Varga L. "Nuts and bolts" of laboratory evaluation of angioedema. Clin Rev Allergy Immunol. 2016;51(2):140-51.

5. Zingale LC, Beltrami L, Zanichelli A, Maggioni L, Pappalardo E, Cicardi B, Cicardi M. Angioedema without urticaria: a large clinical survey. CMAJ. 2006;175(9):1065-70.

6. González P, Soriano V, Caballero T, Niveiro E. Idiopatic angioedema treated with dapsone. Allergol Immunopathol. 2005;33(1):54-6.

7. Del Corso I, Puxeddu I, Sardano E, Geraci S, Breggia M, Rocchi V, Migliorini P. Treatment of idiopathic nonhistaminergic angioedema with bradykinin B2 receptor antagonist icatibant. Ann Allergy Asthma Immunol. 2012;108(6):460-1.

8. Ghazan-Shahi S, Ellis AK. Severe steroid-dependent idiopathic angioedema with response to rituximab. Ann Allergy Asthma Immunol. 2011:107(4):374-6.

9. Shroba J, Hanson J, Portnoy J. Current treatment options for idiopathic angioedema. Ann Allergy Asthma Immunol. 2015;115(5):429-33.
10. Stahl MC, Harris CK, Matto S, Bernstein JA. Idiopathic nonhistaminergic angioedema successfully treated with ecallantide, icatibant, and C1 esterase inhibitor replacement. J Allergy Clin Immunol Pract. 2014;2(6):818-9.

11. Azofra J, Díaz C, Antépara I, Jaúregui I, Soriano A, Ferrer M. Positive response to omalizumab in patients with acquired idiopathic nonhistaminergic angioedema. Ann Allergy Asthma Immunol. 2015;114(5):418-9.

12. Gravante C, Carucci L, Bova M, Petraroli A, Genovese A, Marone G. Prophylactic treatment with plasma-derived $C 1$ inhibitor in idiopathic nonhistaminergic angioedema. Pediatr Allergy Immunol. 2016;27(6):658-9.

13. Frenkel A, Roy-Shapira A, Evgeni B, Leonid K, Borer A, Klein M. Life threatening idiopathic recurrent angioedema responding to cannabis. Case Rep Immunol. 2015;2015:780824.

14. Faisant C, Boccon-Gibod I, Mansard C, Dumestre Perard C, Pralong P, Chatain C, Deroux A, Bouillet L. Idiopathic histaminergic angioedema without wheals: a case series of 31 patients. Clin Exp Immunol. 2016;185(1):81-5.

15. Mansi M, Zanichelli A, Coerezza A, Suffritti C, Wu MA, Vacchini R, Stieber C, Cichon S, Cicardi M. Presentation, diagnosis and treatment of angioedema without wheals: a retrospective analysis of a cohort of 1058 patients. J Intern Med. 2015;277(5):585-93.

\section{Submit your next manuscript to BioMed Central and we will help you at every step:}

- We accept pre-submission inquiries

- Our selector tool helps you to find the most relevant journal

- We provide round the clock customer support

- Convenient online submission

- Thorough peer review

- Inclusion in PubMed and all major indexing services

- Maximum visibility for your research

Submit your manuscript at www.biomedcentral.com/submit 